\title{
Crystallographic Orientation Effect on Electromigration in Ni-Sn Microbump
}

\author{
YI-TING HUANG, ${ }^{1}$ CHIH-HAO CHEN, ${ }^{1}$ SUBHENDU CHAKROBORTY, ${ }^{1}$ \\ and ALBERT T. WU ${ }^{1,2}$ \\ 1.-Department of Chemical and Materials Engineering, National Central University, Jhongli \\ District, Taoyüan City 320, Taiwan. 2.—e-mail: atwu@ncu.edu.tw
}

\begin{abstract}
This article addresses the reliability challenges regarding electromigration in developing three-dimensional integrated circuits (3D-ICs). The line-type sandwich structure of $\mathrm{Ni} / \mathrm{Sn} 3.5 \mathrm{Ag}(15 \mu \mathrm{m}) / \mathrm{Ni}$ was used to simulate microbumps to examine the reliability of electromigration in 3D-IC technology. The solder strip of $\mathrm{Ni} / \mathrm{Sn} 3.5 \mathrm{Ag}(15 \mu \mathrm{m}) / \mathrm{Ni}$ was stressed with a current density of $1.0 \times 10^{4} \mathrm{~A} / \mathrm{cm}^{2}$ at $150^{\circ} \mathrm{C}$. The current stressing enhanced the reaction between the solder and $\mathrm{Ni}$ to form $\mathrm{Ni}_{3} \mathrm{Sn}_{4}$, which occupied the entire joint and transformed into a $\mathrm{Ni} / \mathrm{Ni}_{3} \mathrm{Sn}_{4} / \mathrm{Ni}$ structure when the solder was completely consumed. Electron backscatter diffraction was used to analyze the crystallographic characteristics of $\mathrm{Sn}$ and $\mathrm{Ni}_{3} \mathrm{Sn}_{4}$ as related to the electromigration effect. The results indicated that the crystallographic orientation of Sn plays a significant role in the $\mathrm{Ni} / \mathrm{Sn} 3.5 \mathrm{Ag} / \mathrm{Ni}$, whereas the orientation of $\mathrm{Ni}_{3} \mathrm{Sn}_{4}$ is the dominant factor of diffusion behavior in the $\mathrm{Ni} / \mathrm{Ni}_{3} \mathrm{Sn}_{4} / \mathrm{Ni}$.
\end{abstract}

\section{INTRODUCTION}

$\mathrm{Ni} / \mathrm{Sn}$ is one of the commonly used binary metallic systems in microelectronic packaging. The slow reaction rate of $\mathrm{Ni}$ with $\mathrm{Sn}$-based solder serves as a good diffusion barrier. The approach of using $\mathrm{Ni}$ under bump metallurgy (UBM) with Sn solder has been widely investigated, ${ }^{1,2}$ especially the $\mathrm{Sn}$ grain orientation failure mechanism under current stressing in a three-dimensional integrated circuit (3DIC). ${ }^{3-6}$ These results have indicated that when the $c$-axis of Sn was parallel to the current direction, the dominant diffusion species easily diffused through the solder and caused the circuit failure. Therefore, the relation between the current direction and the Sn orientation can determine the diffusion rate of atomic transportation.

Nevertheless, the on-going miniaturization and the higher packaging density in the semiconductors have resulted in the sizes of solder joints decreasing dramatically. Therefore, during the assembly and operation of the devices, the solder is consumed and transformed into an intermetallic compound (IMC) that occupies a large proportion of the solder joint volume. Additionally, the impingement phenomenon occurs from the opposite interface and the IMC joints determine the reliability in 3D-IC packaging. ${ }^{7}$ Hence, the mechanical and electrical properties of IMCs formed in the limited volume of microbump will be significantly different from traditional large joints.

In recent times, the characteristics and reliabilities of the microbump have attracted tremendous interest from researchers seeking to investigate the formation and orientation of IMCs in the microbump. Lin et al. ${ }^{8}$ found that the preferential growth of $\mathrm{Cu}_{6} \mathrm{Sn}_{5}$ on $\mathrm{Cu} \mathrm{UBM}$ with $<111>$ orientation and nanotwinned changed from the $\{0001\}$ to the $\{2 \overline{11} 3\}$ texture after annealing. Zou et al. ${ }^{9}$ confirmed that special orientation relations existed at the interfaces between the faceted IMC/(001), faceted IMC/ (111), and scallop-like IMC/(011) single-crystal $\mathrm{Cu}$ substrate. Zhang et al. ${ }^{10}$ claimed that the $\mathrm{Cu}_{3} \mathrm{Sn}$ grain had a preferred orientation along (100) being parallel to the $\mathrm{Cu}$ substrate after annealing. Wang et al. ${ }^{11}$ suggested that a $\mathrm{Cu}_{3} \mathrm{Sn}$ grain may possess uniform grain boundary energy. Furthermore, Chen et al. ${ }^{12}$ investigated the electromigration (EM)induced growth of $\mathrm{Cu}_{3} \mathrm{Sn}$ in a $\mathrm{Cu}_{3} \mathrm{Sn} / \mathrm{Cu}_{6} \mathrm{Sn}_{5} / \mathrm{Cu}_{3} \mathrm{Sn}$ structure and determined that a preferred direction $<010>$ is induced in $\mathrm{Cu}_{3} \mathrm{Sn}$ along the current 
direction on the anode. From these studies, it can be concluded that the characteristics of the IMC orientation in microbumps must be considered on EM.

Notably, in most of the previous studies, the orientation of IMC joints concentrated on the $\mathrm{Cu} / \mathrm{Sn}$ system is dealt with. Only a few electron backscatter diffraction (EBSD) studies have been performed on electromigration in $\mathrm{Ni} / \mathrm{Sn}$ systems as it is difficult to prepare the $\mathrm{Ni}_{3} \mathrm{Sn}_{4}$ IMC joint sample. Additionally, $\mathrm{Ni}_{3} \mathrm{Sn}_{4}$ has a monoclinic crystal structure with lattice parameters, $a=12.2 \mathrm{~nm}$, $b=4.06 \mathrm{~nm}, c=5.21 \mathrm{~nm}$, and $\beta=105^{\circ}$, and is hard to analyze by EBSD because of the strong geometrical pseudosymmetry that exists in the monoclinic lattice. ${ }^{13,14}$ Accordingly, the evolution of $\mathrm{Ni}_{3} \mathrm{Sn}_{4}$ crystallographic characteristics during electromigration has not been exhaustively studied in the literature. In this study, an in situ electromigration test was performed using the sample of Ni/Sn3.5Ag/ $\mathrm{Ni}$ and an EBSD measurement conducted at the same time, thus, allowing the relation between the orientation of $\mathrm{Ni}_{3} \mathrm{Sn}_{4}$ and current direction in $\mathrm{Ni} /$ $\mathrm{Sn} 3.5 \mathrm{Ag} / \mathrm{Ni}$ sandwich configurations to be explored. It has been reported that the orientation of the Sn can be controlled by the current densities. ${ }^{15}$ Furthermore, Suh et al. ${ }^{16}$ suggested that the orientation of the grains of the $\mathrm{Ni}$ substrates directly correlates to the orientation of the $\mathrm{Ni}_{3} \mathrm{Sn}_{4}$. Wang et al. ${ }^{17}$ also proposed that the morphology and grain sizes of $\mathrm{Ni}_{3} \mathrm{Sn}_{4}$ are greatly affected by the $\mathrm{Ni}$ content in liquid Sn. The study is aimed at establishing a model based on the orientation of $\mathrm{Ni}_{3} \mathrm{Sn}_{4}$ grains that will provide useful information for optimizing microelectronic packaging and preventing the degradation of the interconnect technology.

\section{EXPERIMENT}

An efficient method was devised for fabricating sandwich interconnects of $\mathrm{Ni} / \mathrm{Sn} 3.5 \mathrm{Ag} / \mathrm{Ni}$ to investigate the orientation of $\mathrm{Ni}_{3} \mathrm{Sn}_{4}$ grains. The Ushaped grooves were fabricated on silicon wafers using lithographic and etching techniques. A thin $\mathrm{SiO}_{2}$ layer $(200 \mathrm{~nm})$ was grown as a passive layer using Unaxis PECVD. Then, the electron-beam evaporation was used to deposit layers of $\mathrm{Ti}$ $(150 \mathrm{~nm})$ and $\mathrm{Ni}(150 \mathrm{~nm})$ at the substrate as adhesion and seed layers, respectively. Then $\mathrm{Ni}$ electrodes with $7 \mu \mathrm{m}$ in thickness were electroplated on the patterned substrate. The Sn3.5Ag solder was reflowed into the $15-\mu \mathrm{m}$-wide gap between the two electrodes at $240^{\circ} \mathrm{C}$ for $10 \mathrm{~s}$. After the fabrication of the specimens, the in situ EM tests were conducted using a current density of $1.0 \times 10^{4} \mathrm{~A} / \mathrm{cm}^{2}$ at $150^{\circ} \mathrm{C}$. Scanning electron microscopy (SEM) was used to analyze the morphology of the formed compound and to evaluate the reliability of the U-groove solder line. The EBSD technique was used to determine the crystallographic characteristics of the $\mathrm{Sn} 3.5 \mathrm{Ag}$ solder and $\mathrm{Ni}_{3} \mathrm{Sn}_{4}$ under current stressing conditions. In the EBSD analysis, normal direction (ND), rolling direction (RD), and transverse direction (TD) represented the direction normal to the polish surface, parallel to the $\mathrm{Ni} /$ $\mathrm{Sn} 3.5 \mathrm{Ag} / \mathrm{Ni}$ interface, and normal to the $\mathrm{Ni} /$ $\mathrm{Sn} 3.5 \mathrm{Ag} / \mathrm{Ni}$ interface, respectively. In addition, the direction of current was parallel to the TD and perpendicular to the $\mathrm{RD}$.

\section{RESULTS AND DISCUSSION}

To investigate the interfacial IMC evolution during EM, the samples were tested at a current density of $1 \times 10^{4} \mathrm{~A} / \mathrm{cm}^{2}$ at $150^{\circ} \mathrm{C}$. Figure 1 shows the plain-view backscattered electron (BSE) micrographs in the left column and EBSD image quality (IQ) phase maps in the right column of the microjoints captured after 200, 400, and $600 \mathrm{~h}$. The direction of current is indicated by the vertical arrow with the symbol $e^{-}$. The IMC layer of $\mathrm{Ni}_{3} \mathrm{Sn}_{4}$ gradually became thick on both sides and contacted each other from opposite interfaces after $200 \mathrm{~h}$ of current stressing; notably, they were not merged together like $\mathrm{Cu}_{6} \mathrm{Sn}_{5}$ and formed a crack at the contacted interface, as shown in Fig. 1e. Additionally, the total $\mathrm{Sn}$ solder in $\mathrm{Ni} / \mathrm{Sn} 3.5 \mathrm{Ag} / \mathrm{Ni}$ reacted approximately with a $\mathrm{Ni} / \mathrm{Ni}_{3} \mathrm{Sn}_{4} / \mathrm{Ni}$ layer structure, as shown in Fig. 1e and f. Another interesting microstructure was the evolution of the $\mathrm{Ni}_{3} \mathrm{Sn}_{4}$ grain size with time. The TD orientation maps shown in Fig. 1 revealed that as a result of the ripening effect, the grains of $\mathrm{Ni}_{3} \mathrm{Sn}_{4}$ merged into the neighboring grains, thereby increasing the grain size. The grain size of $\mathrm{Ni}_{3} \mathrm{Sn}_{4}$ at the cathode side was smaller than that at the anode side, implying that the dominant diffusion atoms of Ni migrated from the cathode side as a consequence of electromigration.

Figure 2 shows the three EBSD IQ-phase maps of $\mathrm{Ni} / \mathrm{Sn} 3.5 \mathrm{Ag} / \mathrm{Ni}$ captured at different times under similar EM conditions. The images were taken from samples I, II, and III. These samples were fabricated by the same approach and the same materials. The testing current conditions were identical for all samples, but the time to observe for each sample was different. The grains with different orientations were represented by different colors. Because of the limited solder volume in the microjoints, the Sn microstructure only comprised one or two grains between the $\mathrm{Ni}_{3} \mathrm{Sn}_{4}$ layers. The orientation of $\mathrm{Sn}$ grains were signed with the corresponding unit cell at the sites of individual Sn grains in the EBSD maps, which are denoted as grains \#1 to \#3, as shown in Fig. 2a, d, and g. The disorientation angles of the Sn $c$-axis grain \#1 and grain \#2 were determined from the EBSD analysis to be $16.9^{\circ}$ and $32.2^{\circ}$, respectively, which were closely aligned with the current direction; furthermore, a large disorientation angle measuring $55.48^{\circ}$ of Sn $c$-axis for grain \#3 aligned with the electric current. Based on the fact that the $\beta$-Sn comprises a body-centered tetragonal structure with a highly anisotropic 

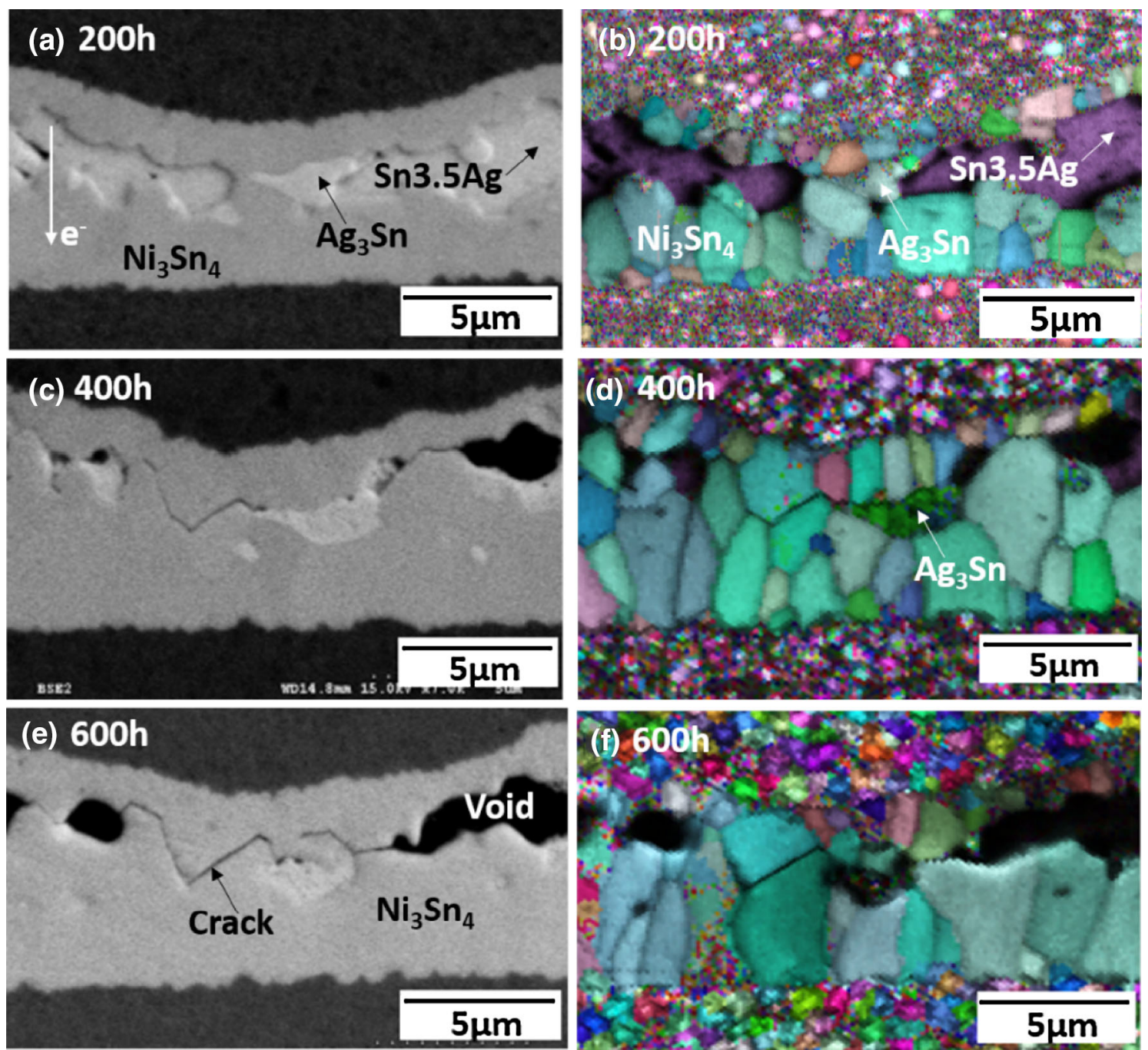

Fig. 1. BSE micrographs of Ni/Sn3.5Ag/Ni with current density of $1 \times 10^{4} \mathrm{~A} / \mathrm{cm}^{2}$ at $150^{\circ} \mathrm{C}$ for (a) $200 \mathrm{~h}$, (c) $400 \mathrm{~h}$, and (e) $600 \mathrm{~h}$. BSED IQ phase maps of (b, d, and f) corresponding to (a, c, and e), respectively.

diffusion behavior, the diffusion atoms would be driven rapidly away from the cathode interface as the Sn $c$-axis grain nearly aligns with the current direction. ${ }^{18}$ Therefore, $\mathrm{Ni}$ atoms in the Sn grain \#1 quickly diffused to the anode interface and reacted with $\mathrm{Sn}$ to form $\mathrm{Ni}_{3} \mathrm{Sn}_{4}$, as shown in Fig. 2a. In contrast, a slow growth rate of $\mathrm{Ni}_{3} \mathrm{Sn}_{4}$ in sample III was exhibited as the Sn $c$-axis grain \#3 possessed a large angle with respect to the current direction, as shown in Fig. 2g. This demonstrated that the $\mathrm{Ni}_{3} \mathrm{Sn}_{4}$ growth rate in the $\mathrm{Ni} / \mathrm{Sn} 3.5 \mathrm{Ag} / \mathrm{Ni}$ diffusion couple depends strongly on the $\beta$-Sn crystallographic orientation under electromigration.

When the EM time was prolonged, the Sn solder reacted with $\mathrm{Ni}$ atoms and was totally consumed resulting in the conversion of the solder joints into IMC joints. The investigation of the preferential relation between $\mathrm{Ni}_{3} \mathrm{Sn}_{4}$ orientation and electromigration effect is important in real packaging microjoints. The TD orientation maps of the $\mathrm{Ni}_{3} \mathrm{Sn}_{4}$ joints and (010) pole figures of the $\mathrm{Ni}_{3} \mathrm{Sn}_{4}$ are shown in Fig. 2. The (010) pole figures corresponding to the orientation maps of $\mathrm{Ni}_{3} \mathrm{Sn}_{4}$ grains in Fig. 2b, e, and $\mathrm{h}$ are shown in Fig. $2 \mathrm{c}, \mathrm{f}$, and $\mathrm{i}$, respectively. In this study, no obvious preferred orientation of $\mathrm{Ni}_{3} \mathrm{Sn}_{4}$ grains was obtained when the $\mathrm{Sn} c$-axis was nearly parallel to the current direction owing to the fast growth rate of $\mathrm{Ni}_{3} \mathrm{Sn}_{4}$, such as that in sample I in Fig. $2 \mathrm{~b}$ and c. Nevertheless, when the growth rate of $\mathrm{Ni}_{3} \mathrm{Sn}_{4}$ was retarded by the $\mathrm{Sn}$ grain orientation, the monoclinic $\mathrm{Ni}_{3} \mathrm{Sn}_{4}$ orientation was approximately green in color on the indexation with $\mathrm{Ni}_{3} \mathrm{Sn}_{4}$, indicating that the $\mathrm{Ni}_{3} \mathrm{Sn}_{4}$ possessed a (100) crystal direction, as shown in Fig. $2 \mathrm{~h}$ and $\mathrm{k}$. Additionally, in the (010) pole figure shown in Fig. 2i, the red areas were mainly located at both ends of TD axes, which meant that the $(010)$ plane of $\mathrm{Ni}_{3} \mathrm{Sn}_{4}$ with a monoclinic structure tended to be perpendicular to 
Sample I
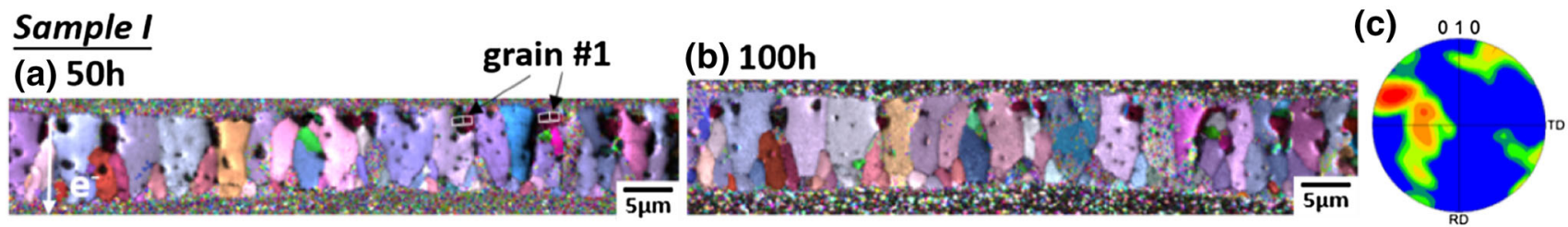

\section{Sample II}

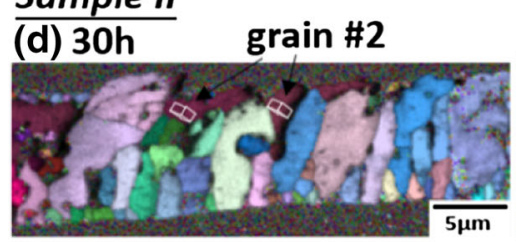

(e) $200 \mathrm{~h}$

(f)
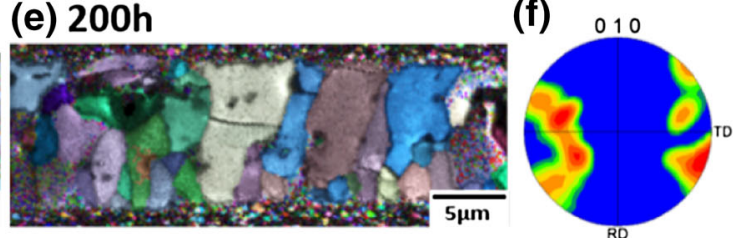

\section{Sample III}

(g) $400 \mathrm{~h}$ grain \#3

(h) $600 \mathrm{~h}$
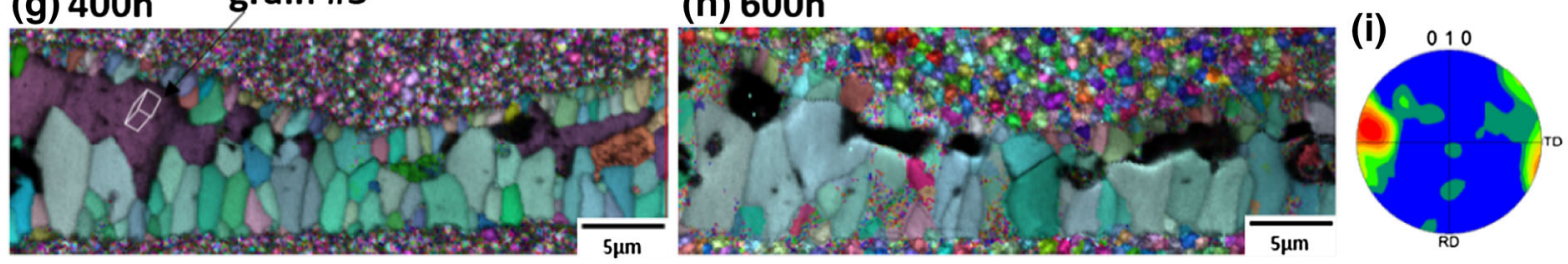

(j) Sn

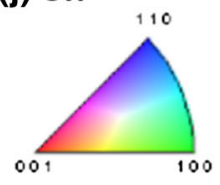

(k) $\mathrm{Ni}_{3} \mathrm{Sn}_{4}$
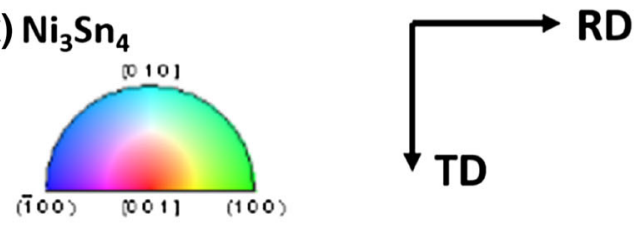

Fig. 2. Orientation maps of $\mathrm{Ni}_{3} \mathrm{Sn}_{4}$ joints after current stressing in sample I (a, b), sample II (d, e), and sample III (g, h). (010) pole figures of $\mathrm{Ni}_{3} \mathrm{Sn}_{4}$ of (c, f, and i) corresponding to each sample (I, II, and III), respectively. The reference figure of $\mathrm{Sn}$ and $\mathrm{Ni}_{3} \mathrm{Sn}_{4}(\mathrm{j}, \mathrm{k})$.

Table I. Disorientation angles of $\mathrm{Ni}_{3} \mathrm{Sn}_{4} a$-axis, $b$-axis, and current direction, corresponding to Fig. 4

\begin{tabular}{|c|c|c|c|}
\hline \multirow{4}{*}{$\begin{array}{l}a \text {-axis of } \mathrm{Ni}_{3} \mathrm{Sn}_{4} \\
b \text {-axis of } \mathrm{Ni}_{3} \mathrm{Sn}_{4} \\
\end{array}$} & \multicolumn{3}{|c|}{ Grain size increased } \\
\hline & G\#1 & G\#3 & G\#6 \\
\hline & $60.10^{\circ}$ & $56.01^{\circ}$ & $52.23^{\circ}$ \\
\hline & $42.10^{\circ}$ & $34.75^{\circ}$ & $39.50^{\circ}$ \\
\hline & \multicolumn{3}{|c|}{ Grain size decreased } \\
\hline & G\#2 & G\#4 & G\#5 \\
\hline$a$-axis of $\mathrm{Ni}_{3} \mathrm{Sn}_{4}$ & $68.41^{\circ}$ & $63.59^{\circ}$ & $69.56^{\circ}$ \\
\hline$b$-axis of $\mathrm{Ni}_{3} \mathrm{Sn}_{4}$ & $24.83^{\circ}$ & $27.13^{\circ}$ & $37.56^{\circ}$ \\
\hline
\end{tabular}

the RD-TD planes. The [010] direction of $\mathrm{Ni}_{3} \mathrm{Sn}_{4}$ was parallel to TD axes with a slight deviation. Therefore, the unique preferred orientation of $\mathrm{Ni}_{3} \mathrm{Sn}_{4}$ under current stressing resulted from the Sn orientation relation with the current direction.

An additional study based on EBSD was conducted to establish the correlation between the $\mathrm{Ni}_{3} \mathrm{Sn}_{4}$ orientation and the current direction in IMC joints. The ripening growth of $\mathrm{Ni}_{3} \mathrm{Sn}_{4}$ grains gradually occurred during the application of the current stressing on the microbumps. Figure 3a to c shows histograms of the statistical distribution of the grain sizes for samples I, II, and III. The data adopted in these figures are the comparison between short-and long-term current stressing. It can be clearly seen that the grain sizes indeed increased under electromigration. As a result, $\mathrm{Ni}_{3} \mathrm{Sn}_{4}$ occupied the microbump and dominated 
(a)

\section{Sample-I}
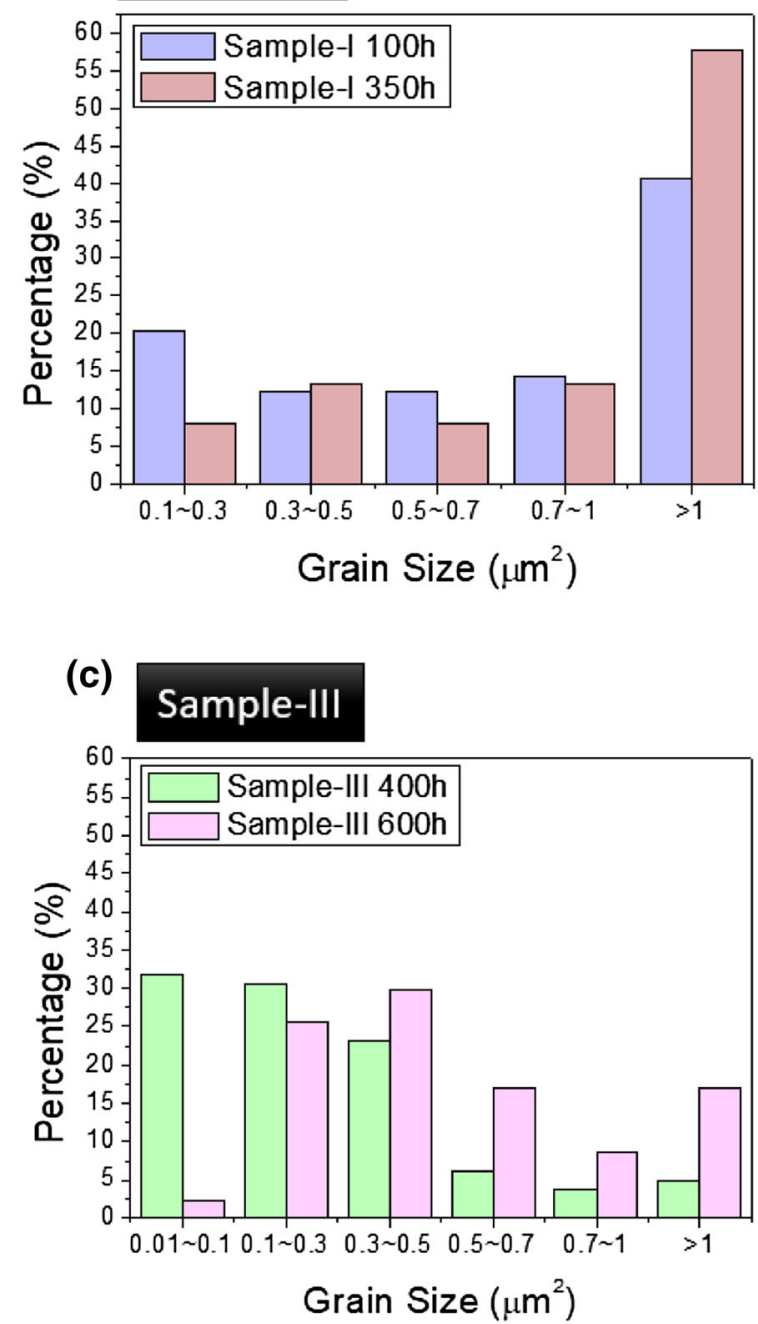

(b)

Sample-II

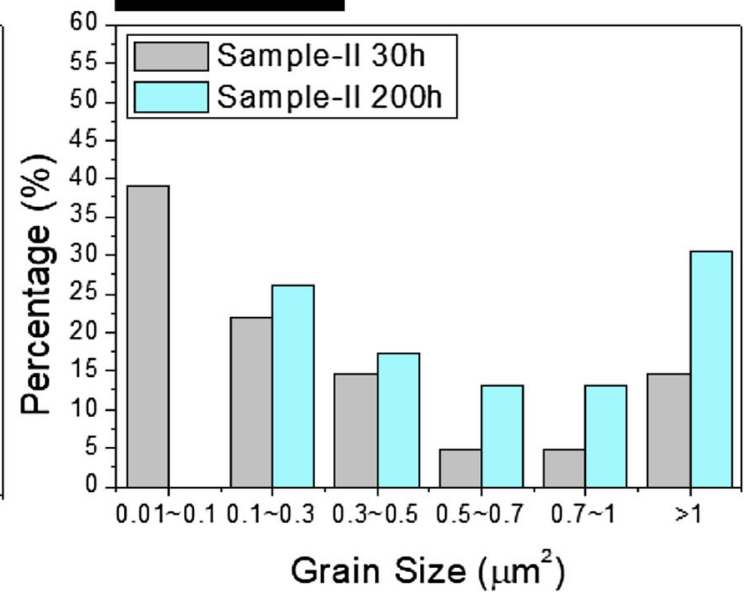

Fig. 3. Statistical distribution of the grain size in samples I, II, and III with different EM times.

the diffusion behavior under electromigration. To understand the phenomenon of merging of $\mathrm{Ni}_{3} \mathrm{Sn}_{4}$ grains, an investigation was conducted using the TD orientation maps of interfacial $\mathrm{Ni}_{3} \mathrm{Sn}_{4}$ evolution with time after passing the current stressing in three regions on two specimens. The specimens are marked by a dotted line and are denoted by G\# 1 to G\#6 in Fig. 4. In each region, there were two IMC grains in contact; one expanded as the grain size grew with EM times, whereas the other shrunk as a result of the restricted space of the microbump that was occupied by the IMC. For example, in region 1, the grain size of G\#1 increased and that of $\mathrm{G} \# 2$ decreased after current stressing. The exact orientation of each $\mathrm{Ni}_{3} \mathrm{Sn}_{4}$ grain was presented by the corresponding unit cell in Fig. 4e. The red and green colors represented the $a$-axis and $b$-axis of $\mathrm{Ni}_{3} \mathrm{Sn}_{4}$ grain orientation, respectively. The disorientation angles of $a$-axis and $b$-axis of $\mathrm{Ni}_{3} \mathrm{Sn}_{4}$ in the current direction were analyzed using EBSD and listed in Table I.

As illustrated in Fig. 4 and Table I, when the two grains started merging together, the orientation of $\mathrm{Ni}_{3} \mathrm{Sn}_{4}$ possessed a small disorientation angle between the $\mathrm{Ni}_{3} \mathrm{Sn}_{4} a$-axis and the current direction and a big disorientation angle between the $\mathrm{Ni}_{3} \mathrm{Sn}_{4}$ $b$-axis and the current direction that caused the grain size to increase with the EM times, such as that in G\#1, G\#3, and G\#6. On the contrary, the decrease in the grain size was characterized by a big disorientation angle between the $\mathrm{Ni}_{3} \mathrm{Sn}_{4} a$-axis and the current direction and by a small disorientation angle between the $\mathrm{Ni}_{3} \mathrm{Sn}_{4} b$-axis and the current direction, such as that in G\#2, G\#4, and G\#5. Additionally, an in situ study clarified that the crystallographic orientation of $\mathrm{Ni}_{3} \mathrm{Sn}_{4}$ did not 


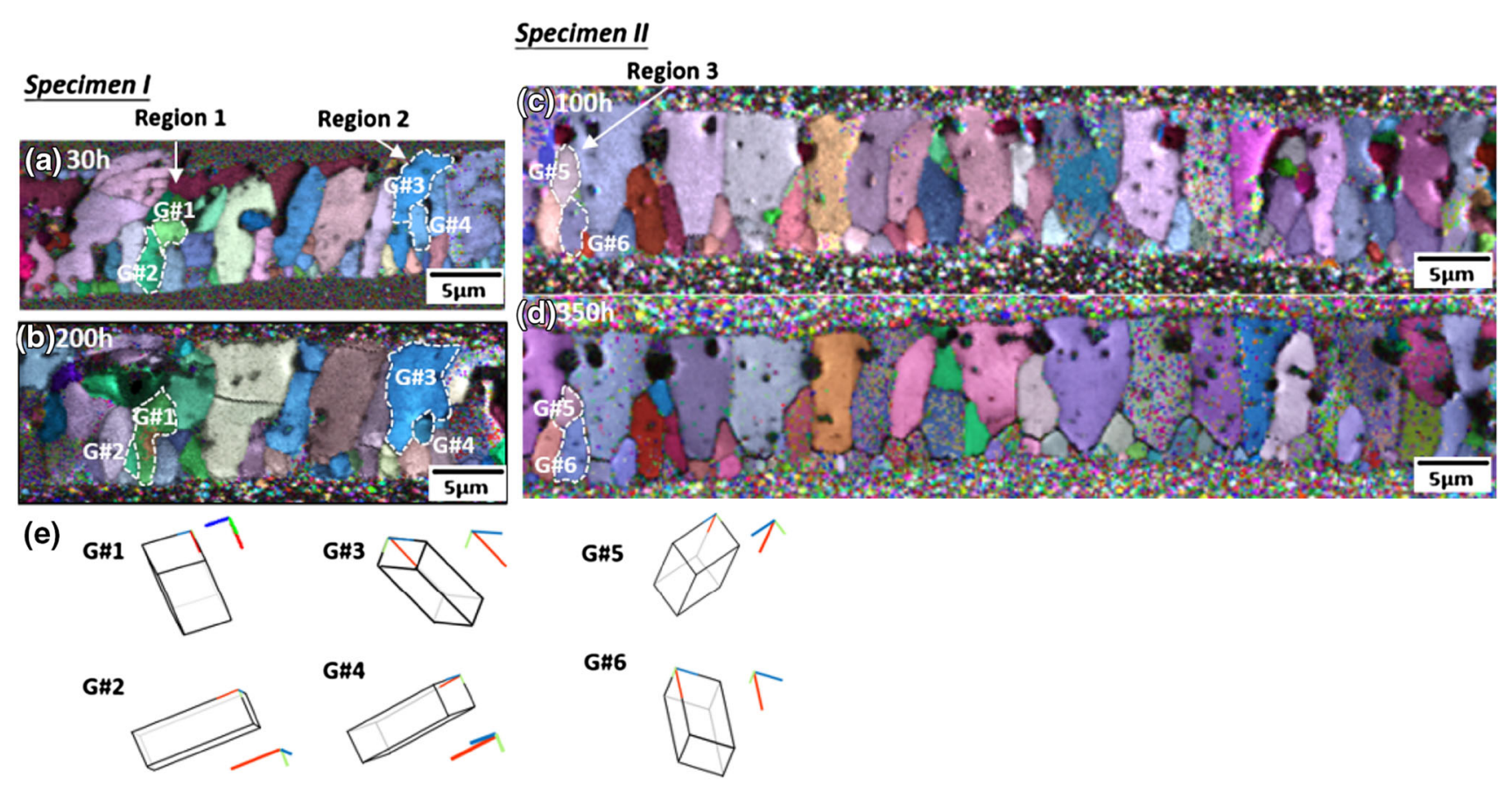

Fig. 4. Orientation of $\mathrm{Ni}_{3} \mathrm{Sn}_{4}$ evolution with EM times in specimen I (a) $30 \mathrm{~h}$, (b) $200 \mathrm{~h}$, and specimen II (c) $100 \mathrm{~h}$, (d) $350 \mathrm{~h}$, and (e) unit cell orientation of $\mathrm{Ni}_{3} \mathrm{Sn}_{4}$.

Table II. Initial Ni flux under EM in each grain, corresponding to the regions in Fig. 4

\begin{tabular}{cll}
\hline Region I & & Diffusivity $\left(\mathrm{cm}^{2} / \mathrm{s}\right)$ \\
Grain A & G\#2 & $D=1.22 \times 10^{-9}$ \\
Grain B & G\#1 & $D=2.75 \times 10^{-10}$ \\
Region II & & \\
Grain A & G\#4 & $D=1.17 \times 10^{-9}$ \\
Grain B & G\#3 & $D=8.16 \times 10^{-10}$ \\
Region III & & \\
Grain A & G\#5 & $D=7.16 \times 10^{-10}$ \\
Grain B & G\#6 & $D=5.66 \times 10^{-10}$ \\
\hline
\end{tabular}

change with time under current stressing. This observation suggested that the disorientation angle between $\mathrm{Ni}_{3} \mathrm{Sn}_{4}$ and the current direction is a dominant factor affecting the merging phenomenon.

$\mathrm{Ni}$ flux was used to analyze quantitatively the effect of $\mathrm{Ni}_{3} \mathrm{Sn}_{4}$ grain orientation on the grain growth under current stressing. Based on the images in Fig. 4, the aspect ratio of the grains was around 2-3. It clearly shows a difference in growth rate. To simplify the calculation of the $\mathrm{Ni}$ flux caused by electromigration, it is assumed that the grains grow along the direction of the current flow. It was considered to be a simple geometrically merging situation of two grains: A "Grain A" shrank with its $b$-axis directed closely parallel to the current direction, and a "Grain B" grew with its $b$-axis directed nearly perpendicular to the current direction. The Ni flux $\left(J_{\mathrm{EM}}\right)$ induced by the current effect can be represented as follows:

$$
J_{\mathrm{EM}}=\frac{x_{\mathrm{EM}}}{\Omega t}
$$

where $x$ is the dimension of grain growth along the current direction, $\Omega$ is the atomic volume, and $t$ is the time of electromigration. By inserting parameter values into Eq. 1 and combining the equation with Fig. 5, a theoretical value of the Ni flux $\left(J_{\mathrm{EM}}\right)$ as a function of $\mathrm{Ni}_{3} \mathrm{Sn}_{4}$ orientation can be established. The initial Ni flux under EM in each grain at the three regions was calculated and shown in Table II.

Figure 5c schematically depicts the size evolution of two merging $\mathrm{Ni}_{3} \mathrm{Sn}_{4}$ grains with EM. If Grain A were located near the cathode, $\mathrm{Ni}$ atoms would rapidly diffuse through Grain A with a flux $J_{\mathrm{A}}$; if Grain B located near the anode, there will be a flux trough Grain $\mathrm{B}, J_{\mathrm{B}}$. As a result of anisotropy of the grain orientation, the $b$-axis of Grain A was along current flow direction, whereas the $b$-axis of Grain $\mathrm{B}$ was perpendicular to the current. Thus, the flux in Grain A would be greater than in Grain B, $J_{\mathrm{A}}>J_{\mathrm{B}}$, as the value shown in Table II. The unbalanced flux would cause the grain boundaries to move toward the cathode side accompanied with the grain growth of Grain B. If the orientation of the 
(a)

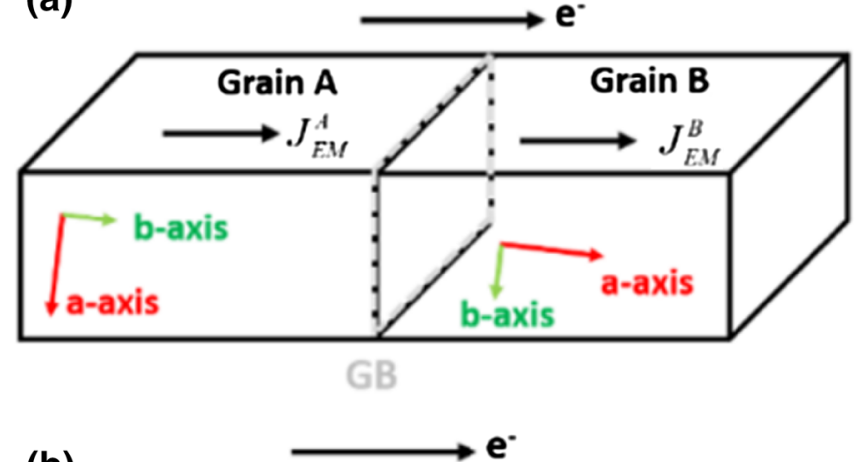

(b)

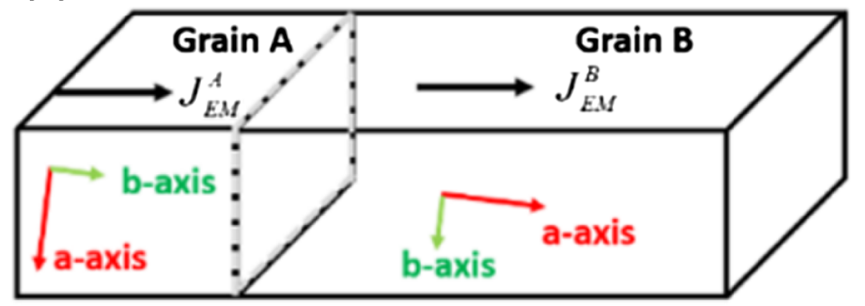

(c)
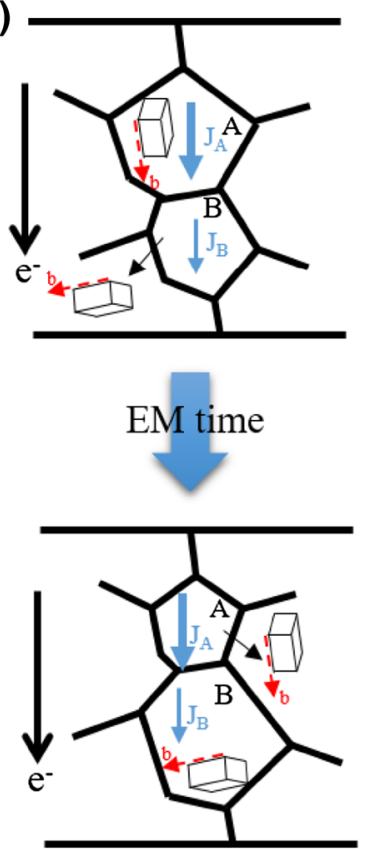

Fig. 5. Schematic figure of $\mathrm{Ni}$ flux in the metal line (a) before merging, (b) after merging, or (c) grain growth resulting from the differences in Ni flux under EM.

$\mathrm{Ni}_{3} \mathrm{Sn}_{4}$ grain can be controlled to form the "Grain B" type, the growth of the grains would lead to be only a few big $\mathrm{Ni}_{3} \mathrm{Sn}_{4}$ grains existing in the IMC microjoints that would, thus, possess a less number of grain boundaries for $\mathrm{Ni}$ diffusion. Accordingly, this would improve the protection of the microjoints in 3D-IC against electromigration. Controlling the orientation of Sn and IMCs requires further study.

\section{CONCLUSION}

A sandwich structure of $\mathrm{Ni} / \mathrm{Sn} 3.5 \mathrm{Ag} / \mathrm{Ni}$ was used to investigate the relation between the current direction and the crystallographic orientation of $\mathrm{Sn}$ and $\mathrm{Ni}_{3} \mathrm{Sn}_{4}$. The solder joints of $\mathrm{Ni} / \mathrm{Sn} 3.5 \mathrm{Ag} / \mathrm{Ni}$ were converted into $\mathrm{Ni} / \mathrm{Ni}_{3} \mathrm{Sn}_{4} / \mathrm{Ni}$ under current stressing at $150^{\circ} \mathrm{C}$. EBSD analysis showed the existence of a big disorientation angles between the Sn $c$-axis and the current direction; moreover, the [010] direction of $\mathrm{Ni}_{3} \mathrm{Sn}_{4}$ was easily paralleled to the current direction with a slight deviation after the transformation from $\mathrm{Ni} / \mathrm{Sn} 3.5 \mathrm{Ag} / \mathrm{Ni}$ to $\mathrm{Ni} /$ $\mathrm{Ni}_{3} \mathrm{Sn}_{4} / \mathrm{Ni}$. The findings of the study also revealed that a solder joint comprising a Sn grain with a large disorientation angle between the Sn $c$-axis and the current flow possesses a slow diffusion rate and better electromigration reliability. The merging phenomenon in the IMC joints comprising $\mathrm{Ni}_{3} \mathrm{Sn}_{4}$ grains entails the reduction of grain size when there is a big disorientation angle between the $\mathrm{Ni}_{3} \mathrm{Sn}_{4} a$ axis and the current direction and a small disorientation angle between the $\mathrm{Ni}_{3} \mathrm{Sn}_{4} b$-axis and the current direction. Thus, the results show that the orientation of $\mathrm{Sn}$ and $\mathrm{Ni}_{3} \mathrm{Sn}_{4}$ grains dominants the
IMC growth rate and affect the electromigration reliability of the solder and microbump joint. This result will benefit 3D-IC technology to control the IMC joint formation as far as the reliability issue of electromigration is concerned.

\section{REFERENCES}

1. T. Laurila, V. Vuorinen, and J.K. Kivilahti, Mater. Sci. Eng. R Rep. 49, 1 (2005).

2. J.J. Yu, J.Y. Wu, S. Yang, and C.R. Kao, ICEP-IAAC Proc. 842, P08 (2015).

3. C. Kinney, X. Linares, K.O. Lee, and J.W. Morris, J. Electron. Mater. 42, 4 (2013).

4. K. Lee, K.S. Kim, T. Tsukada, K. Suganuma, K. Tamanaka, S. Kuritani, and M. Ueshima, J. Mater. Res. 26, 3 (2011).

5. M. Lu, D.Y. Shih, P. Lauro, C. Goldsmith, and D.W. Henderson, Appl. Phys. Lett. 92, 211909 (2008).

6. T.C. Huang, T.L. Yang, J.H. Ke, C.H. Hsueh, and C.R. Kao, Scr. Mater. 80, 37 (2014).

7. W.Y. Chen, W. Tu, H.C. Chang, T.T. Chou, and J.G. Duh, Mater. Lett. 134, 184 (2014).

8. H.W. Lin, C.L. Lu, C.M. Liu, C. Chen, D. Chen, J.C. Kuo, and K.N. Tu, Acta Mater. 61, 4910 (2013).

9. H.F. Zou and Z.F. Zhang, J. Appl. Phys. 108, 103518 (2010).

10. R. Zhang, Y. Tian, C. Hang, B. Liu, and C. Wang, Mater. Lett. 110, 137 (2013).

11. S.J. Wang, L.H. Hsu, N.K. Wang, and C.E. Ho, J. Electron. Mater. 43, 219 (2013).

12. D. Chen, C.E. Ho, and J.C. Kuo, Mater. Lett. 65, 1276 (2011).

13. W. Jeitschko and B. Jaberg, Acta Cryst. B38, B598 (1982).

14. H. Yang and C.T. Prewitt, Am. Min. 84, 929 (1999).

15. S.K. Lin, K. Suganuma, and S.W. Chen, J. Mater. Res. 22, 7 (2007).

16. J.O. Suh, K.N. Tu, A.T. Wu, and N. Tamura, J. Appl. Phys. 109, 123513 (2011).

17. C.H. Wang and J.L. Liu, Intermetallics 61, 9 (2015).

18. C.E. Ho, C.H. Yang, and L.H. Hsu, Surf. Coat. Tech. 259, 257 (2014). 